\title{
Pengelompokkan Pola Persediaan Inventaris Sekolah rakyat Pancurbatu dengan Data Mining Metode Apriori
}

\author{
Yonata Laia*, Tomi D. Bangun*, Vickash P., Eli S. Simatupang, M Afifuddin Alwy N \\ *Program studi Sistem Informasi, Fakultas Teknologi dan Ilmu Komputer, Universitas Prima indonesia
}

\begin{tabular}{l}
\hline \hline Article Info \\
\hline Article history: \\
Received Jun $15^{\text {th }}, 2021$ \\
Revised Jun $27^{\text {th }}, 2021$ \\
Accepted Jun $29^{\text {th }}, 2021$ \\
\\
\hline Keyword \\
Apriori \\
Data inventaris \\
peminjaman \\
Sekolah
\end{tabular}

\begin{abstract}
Selama ini, proses yang dilakukan untuk mendata alat barang pada Laboratorium yayasan perguruan rakyat pancurbatu masih dengan sistem manual yaitu dengan menggunakan buku besar sebaga media penyimpanan. Hal ini dapat mengakibatkan tingkat kehilangan data inventaris semakin meningkat. Tujuan dari peneltian ini adalah untuk membantu pihak inventaris dan meminimalisir kesalah dalam peminjaman maupun pengembalian inventaris sekolah. Pada penelitian ini menggunakan data inventasi yayasan perguruan rakyat pancurbatu sbagai alat tetsting dengan metode yang digunakan. Hasil dalam penelitian ini dapat di terpakan pada yayasan perguruan rakyat pancurbatu.
\end{abstract}

Copyright $(0) 2021$ STMIK Triguna Dharma. All rights reserved.

\footnotetext{
Corresponding Author:

Nama: Yonata Laia

Sistem Informasi

Universitas Prima Indonesia

*yonatalaia88@gmail.com
}

\section{PENDAHULUAN}

Mengingat saat ini di setiap perusahaan, sekolah dan instittusi apapun itu jumlah pelayanan masayarakat semakin meningkat tidak lagi semakin menurun. Maka dengan itulah setian sistem yang belumnya hanya di lakukan dengan sistem manual sekarang sudah mengarah ke informasi yang lebih cepat dan kurat. Namun kebutuhan informasi yang tinggi untuk mendapatkan pengetahuan yang baru kadang tidak diimbangi dengan penyajian informasi yang memadai [1].

Sekolah adalah salah satu tempat setiap orang menuntut ilmu juga disetiap sekolah ada sistem pembayaran seperti pembayarn spp, osis, pramuka. Maka disetiap sekolah di haruskan agar dapat memantau anak didiknya menjadi menjadi lebih baik dalam sistem beljar, sistem pelayanan harus terpakan dengan baik. Yayasan perguruan rakyat pancurbatu selama ini melakukan pengolahan data secara manual sehingga bagian penanggu jawab inventaris mengalami masalah dalam mendata barang-barang yang sudah dikembalikan dan masih di pinjam.

Data mining adalah bagian dari proses KDD (Knowledge Discovery in Databases) yang terdiri dari beberapa tahapan seperti pemilihan data, pra pengolahan, transformasi, data mining, dan evaluasi hasil[2]. Data mining adalah proses yang memperkerjakan satu atau lebih teknik pembelajaran komputer (machine learning) untuk menganalisis dan mengekstraksi pengetahuan (knowledge) secara otomatis[3].

Menurut Kursini dan Taufiq (2009:149) Datamaining metode apriori termasuk peraturan asosiasi. Selain metode apriori yang sama dengan metode ini adalah metode Generalized Rule Indctiondan Algoritemn Hasd Based(GRIAHB). Yang dimaksud dengan metode GRIAHB teknik datamining dalam menentukan aturan asossiatif antar kombinasi peritem [4].

Pada penelitian ini akan menggunakan data tahun 2017-2020 yang akan di proses nanti pada sistem pengelompokkna. Sitem yang akan di bangun adalah sistem pengelompokkan data dengan datamining metode apriori. 
Berdasarkan uraian diatas penulis akan membuat sistem yang dapat menyelesian masalah di atas dengan penerapan metode apriori dalam pengelompokkan data siswa pada yayasan perguruan rakyat pancurbatu. Diharpakan dengan adanya sistem ini dapat membantu pihak sekoalah dalam pengolahan data induk siswa/i.

\section{METODE PENELITIAN}

Metode apriori adalah metode pengambilan data dengan aturan asosiatif (association rule) untuk menentukan hubungan asosiatif suatu kombinasi item. Association Rule yang dimaksud dilakukan melalui mekanisme perhitungan support dan confidence dari suatu hubungan item. Sebuah rule asosiasi dikatakan interesting jika nilai support adalah lebih besar dari mining supporti dan juga nilai confidence.

Tabel 3.1. Pola Transaksi Persediaaan

\begin{tabular}{|l|l|}
\hline Transaksi & Items \\
\hline 1 & A. Ac samsung, C. Ac mitsubishi, D. Proyektor Epson \\
\hline 2 & A. Ac samsung, B.Kipas angin indachi, C. Ac mitsubishi, D. Proyektor Epson, E. Kursi Dosen \\
\hline 3 & C. Ac mitsubishi, D. Proyektor Epson, E. Kursi Dosen, F. meja \\
\hline 4 & B. Kipas angin indachi, E. Kursi Dosen, F. meja \\
\hline 5 & A. Ac samsung, C. Ac mitsubishi \\
\hline 6 & A. Ac samsung, C. Ac mitsubishi, D. Proyektor Epson \\
\hline 7 & A. Ac samsung, B. Kipas angin indachi, C. Ac mitsubishi, D. Proyektor Epson, E. Kursi Dosen \\
\hline 8 & C. Ac mitsubishi, D. Proyektor Epson, E. Kursi Dosen, F. meja \\
\hline 9 & B. Kipas angin indachi, E. Kursi Dosen, F. meja \\
\hline 10 & A. Ac samsung, C. Ac mitsubishi \\
\hline 11 & A. Ac samsung, C. Ac mitsubishi, D. Proyektor Epson, \\
\hline 12 & A. Ac samsung, B. Kipas angin indachi, C. Ac mitsubishi, D. Proyektor Epson, E. Kursi Dosen, \\
\hline 13 & C. Ac mitsubishi, D. Proyektor Epson, E. Kursi Dosen, F. meja \\
\hline 14 & B. Kipas angin indachi, E. Kursi Dosen, F. meja \\
\hline 15 & A. Ac samsung, C. Ac mitsubishi \\
\hline 16 & A. Ac samsung, C. Ac mitsubishi, D. Proyektor Epson \\
\hline 17 & A. Ac samsung, B. Kipas angin indachi, C. Ac mitsubishi, D. Proyektor Epson, E. Kursi Dosen \\
\hline 18 & C. Ac mitsubishi, D. Proyektor Epson, E. Kursi Dosen, F. meja \\
\hline 19 & B. Kipas angin indachi, E. Kursi Dosen, F. Meja \\
\hline 20 & A. Ac samsung, C. Ac mitsubishi \\
\hline
\end{tabular}

\section{Pembentukan Itemset}

Berikut adalah penyelesaian berdasarkan data yang sudah disediakan pada tabel III.2. Proses pembentukan $\mathrm{C}_{1}$ atau disebut dengan 1 itemset dengan minimum support $=25 \%$ dengan rumus sebagai berikut :

\section{Support A $=$ Jumlah transaksi mengandung A $\sum$ transaksi}

Tabel 3.2. Support Dari tiap Item

\begin{tabular}{|c|c|c|}
\hline Itemset & Jumlah & Support \\
\hline \hline Ac samsung & $12 / 20 \%$ & $60 \%$ \\
\hline Kipas angin indachi & $8 / 20 \%$ & $40 \%$ \\
\hline Ac mitsubishi & $15 / 20 \%$ & $75 \%$ \\
\hline Proyektor Epson & $12 / 20 \%$ & $60 \%$ \\
\hline Kursi Dosen & $12 / 20 \%$ & $60 \%$ \\
\hline Meja & $8 / 20 \%$ & $40 \%$ \\
\hline
\end{tabular}

\section{Kombinasi 2 Itemset}

Proses pembentukan $\mathrm{C}_{2}$ atau disebut dengan 2 itemset dengan Minimum support $=50 \%$. Dapat diselesaikan dengan rums berikut : 


\section{Support $(\mathrm{A}, \mathrm{B})=\mathrm{P}(\mathrm{A} \cap \mathrm{B})$ Support $(\mathrm{A}, \mathrm{B})=$ \\ Jumlah transaksi mengandung $A$ dan $B$}

Total Transaksi

Tabel 3.3. Calon 2-itemset

\begin{tabular}{|c|c|c|}
\hline Itemset & Jumlah & Support \\
\hline Ac samsung, Kipas angin indachi & 4 & $20 \%$ \\
\hline Ac samsung, Ac mitsubishi & 12 & $60 \%$ \\
\hline Ac samsung, Proyektor Epson & 8 & $40 \%$ \\
\hline Ac samsung, Kursi Dosen & 4 & $20 \%$ \\
\hline Ac samsung, meja & 0 & $0 \%$ \\
\hline Kipas angin indachi, Ac mitsubishi & 4 & $20 \%$ \\
\hline Kipas angin indachi, Proyektor Epson, & 6 & $10 \%$ \\
\hline Kipas angin indachi, Kursi Dosen & 12 & $20 \%$ \\
\hline Kipas angin indachi, Meja & 4 & $20 \%$ \\
\hline Ac mitsubishi, Proyektor Epson & 12 & $20 \%$ \\
\hline Ac mitsubishi, Kursi Dosen & 8 & $40 \%$ \\
\hline Ac mitsubishi, meja & 4 & $20 \%$ \\
\hline Proyektor Epson, Kursi Dosen & 8 & $40 \%$ \\
\hline Proyektor Epson, meja & 4 & $20 \%$ \\
\hline Kursi Dosen, meja & 8 & $40 \%$ \\
\hline
\end{tabular}

\section{Pembetukan Aturan Asosiasi}

Setelah semua pola frekuensi tinggi ditemukan, maka langkah selanjutnya Mencari aturan asosiasi yang memenuhi syarat minimum untuk confidence dengan menghitung confidence aturan asosiatif $\mathrm{A} \rightarrow \mathrm{B}$. Minimal confidence $=60 \%$

Nilai confidence dari aturan $\mathrm{A} \rightarrow \mathrm{B}$ diperoleh dengan rumus sebagai berikut :

\section{Confidence $=\mathbf{P}(\mathbf{B} \mid \mathbf{A})=$}

Jumlah transaksi mengandung A dan B Jumlah transaksi mengandung $\mathrm{A}$

Tabel 3.4. Aturan Asosiasi

\begin{tabular}{|c|c|c|}
\hline Aturan & \multicolumn{2}{|c|}{ Confidence } \\
\hline $\begin{array}{c}\text { Jika Ac samsung maka Ac } \\
\text { mitsubishi }\end{array}$ & $12 / 15 * 80$ & $80 \%$ \\
\hline
\end{tabular}

Berdasarkan aturan asosiasi diatas, dapat diketahui Pola Persediaan Inventari Barang Pada Biro Sarana dan Prasarana Universitas Prima.

\section{Hasil Dan Pembahasan}

Berikut ini akan dijelaskan tentang tampilan hasil dari Aplikasi Penerapan Data Mining Menggunakan Metode Apriori Untuk Menyusun Pola Persediaan Inventaris Barang Pada Biro Sarana Dan Prasarana Universitas Prima Indonesia dapat dilihat sebagai berikut :

1. Tampilan Form Login

Tampilan yang disajikan oleh sistem untuk melakukan login admin atau user dapat dilihat pada gambar .1. 


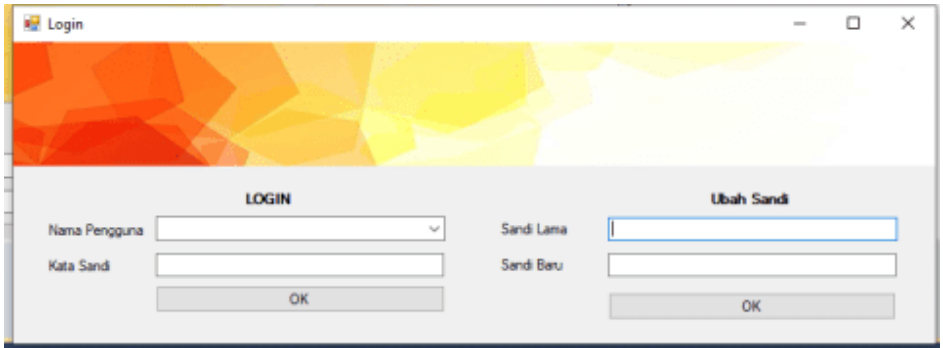

Gambar 1. Tampilan Form Login

2. Tampilan Form Menu Utama

Tampilan yang disajikan oleh sistem untuk menampilkan menu utama dapat dilihat pada gambar 2.

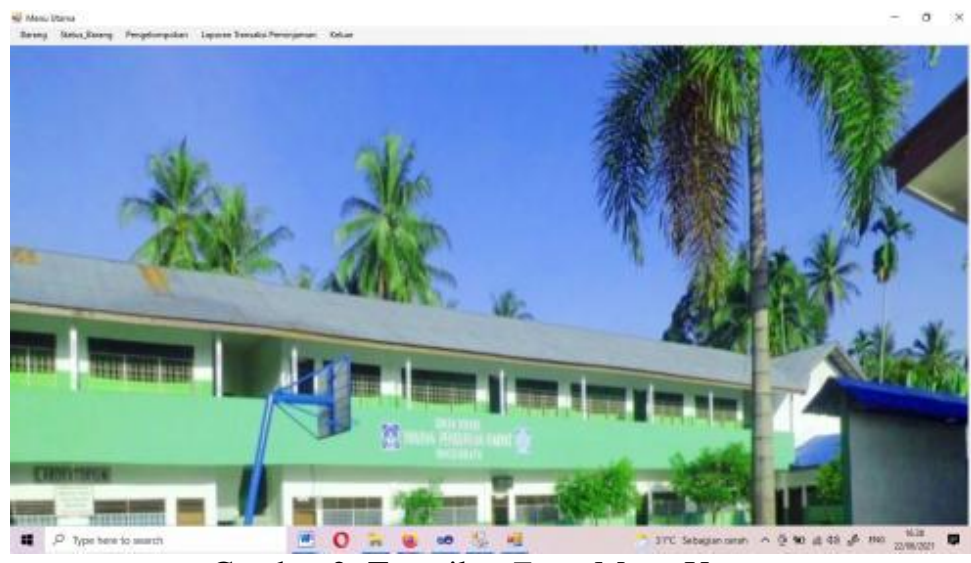

Gambar 2. Tampilan Form Menu Utama

3. Tampilan Form Barang

Tampilan Form Barang disajikan untuk menampilkan data Barang, tampilan form Barang dapat dilihat pada gambar 3.

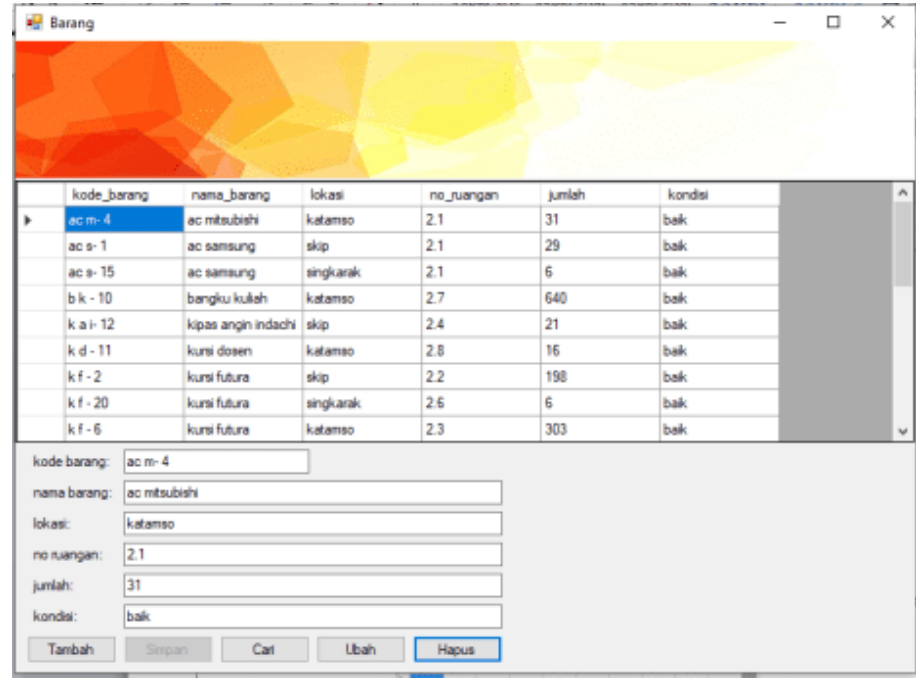

Gambar 3. Tampilan Form Barang

4. Tampilan Form Pengembalian

Tampilan Form Pengembalian disajikan untuk menampilkan data Pengembalian yang tersedia, tampilan form Pengembalian dapat dilihat pada gambar 4 . 


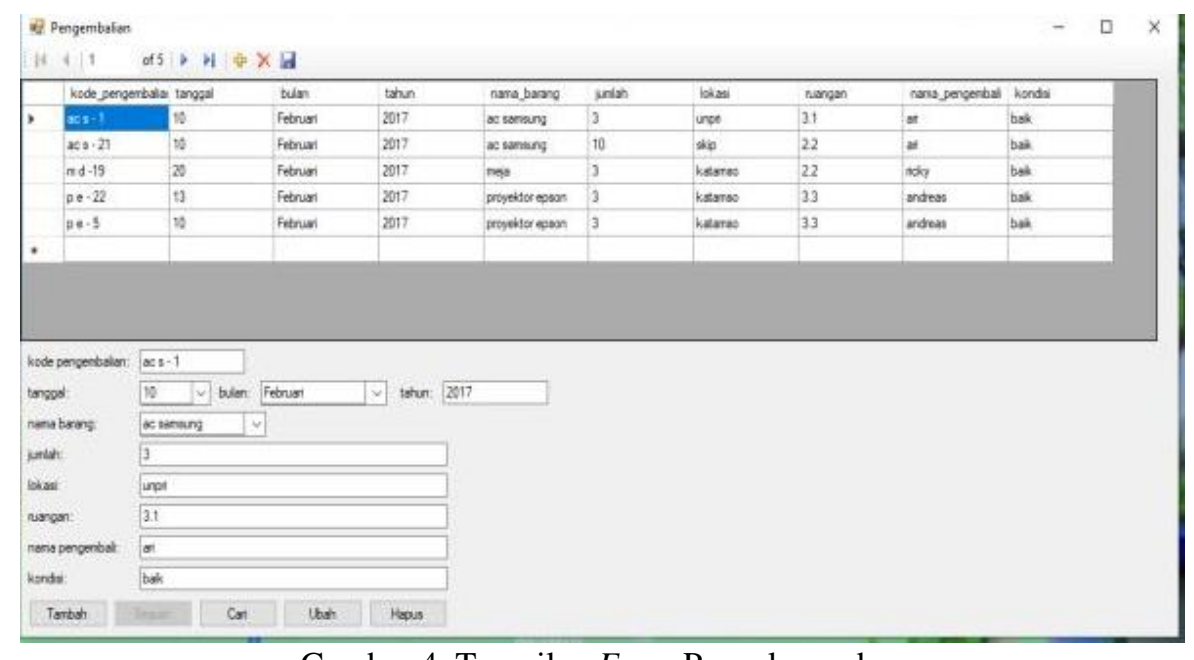

Gambar 4. Tampilan Form Pengelompokan

5. Tampilan Form Laporan Serah Terima Peminjaman Barang

Tampilan Form Laporan Serah Terima Peminjaman Barang disajikan untuk menampilkan Laporan Serah Terima Peminjaman Barang yang tersedia, tampilan form Laporan Serah T SerahTerima Peminjaman Barang dapat dilihat pada gambar 5.

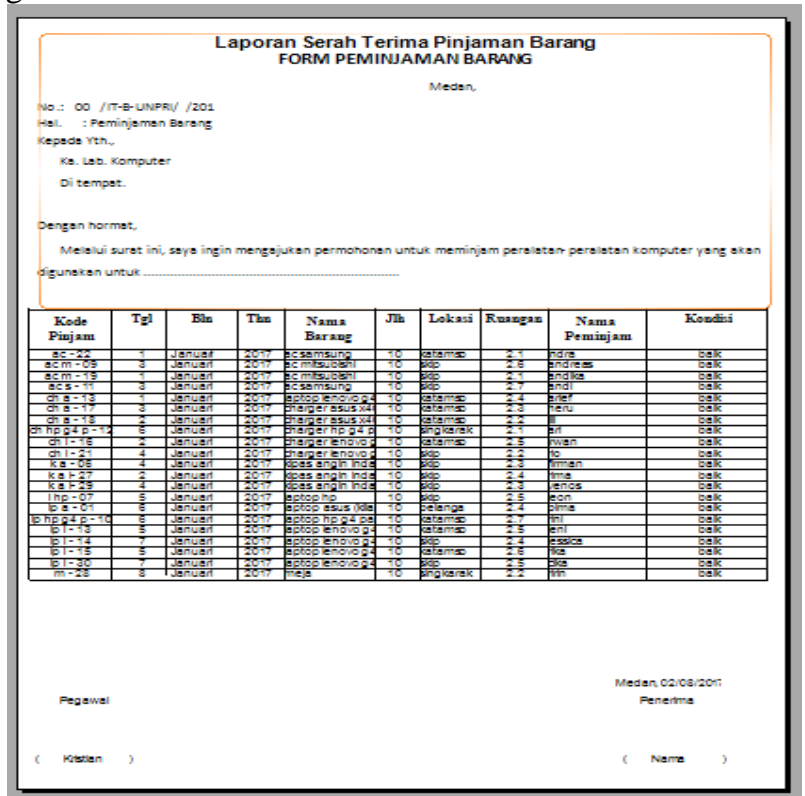

Gambar 5. Tampilan Form Laporan Serah Terima Peminjaman Barang

\section{Kesimpulan}

Berdasarkan hasil dari pembahasan sebelumnya dimana pada sekolah yayasan perguruan rakyat pancurbatu masih melakukan pengolahan datan inventaris sistem naual sehingga sering mengalami kesalah dan keterlambatan pengembalian dikearenakan dalam penyusuan dan pengelompokkan data peminjaman tidak terstruktur. Dengan menggunakan aplikasi ini sistem yang sebelumnya jauh lebih baik dibandingkan dengan sistem pengelompokkan data inveraris dengan datamining metode apriori.

\section{REFERENSI}

[1]. Azimah, A., \& Sucahyo, Y. G. Penggunaan Data Warehouse Dan Data Mining Untuk Data Akademik Sebuah Studi Kasus Pada Universitas Nasional. Jurnal Sistem Informasi MTI UI Vol. 3 No. 2 -Oktober 2007, 1-7.

[2]. Maimon, O. dan Last, M. 2000. “Knowledge Discovery and Data Mining, The Info-Fuzzy Network (IFN) Methodology”. Dordrecht: Kluwer Academic.

[3]. Hermawati, Fajar Astuti.(2013)Data Mining. Yogyakarta: Andi 
[4]. Kursini dan Emha Taufiq Luthfi.(2009)Data Mining. Yogyakarta: Andi

[5]. Prasetyo, Eko, Data Mining-Konsep Dan Aplikasi Menggunakan Matlab, Yogyakarta: ANDI. 2012.

[6]. Kadek Juni I; Indrawan Gede; Rasben, Dantes, Gede "Data Mining Rekomendasi Calon Mahasiswa Berprestasi Di STMIK Denpasar Menggunakan Metode Technique For Others Reference By Similarity To Ideal Solution", Jurnal Sains dan Teknologi, Vol.5, pp.746- 760, 2016.

[7]. Wandi, Nugroho, Rully A. Hendrawan, and Ahmad Mukhlason, "Pengembangan Sistem Rekomendasi Penelusuran Buku dengan Penggalian Association Rule Menggunakan Algoritma Apriori Kearsipan Provinsi Jawa Timur", Jurnal Teknik Its, vol. 1, pp. 445-449, 2012.

[8]. H Hery, Y Laia, C Fenaldi, DS Dao, W Wijaya, Penerapan metode k-nearest nigboar untuk menentukan kualitas buah sawit layak diterima di pt. Cipta chemical medan oil, J-SISKO TECH (Jurnal Teknologi Sistem Informasi dan Sistem Komputer TGD), Vol 3, No. 2, 2018.

[9]. Yonata Laia, Perancangan Sistem Pendukung Keputusan Kenaikan Jabatan Karyawan dengan Metode SMART pada PT. Invilon Sagita Medan, Jurnal Sistem Informasi dan Ilmu Komputer Prima (JUSIKOM PRIMA), Vol 1, No. 12018.

[10]. Yanto, Robi, and Khoiriah, Riri "Implementasi Data Minig dengan Metode Algoritma Apriori dalam Menentukan Pola Pembelian Obat", Citec Journal, vol. 2, pp. 102-113, 2015. 